\title{
ECONOMIC ASPECTS OF COLD FOOD PASTEURIZATION
}

\author{
S. L. Bogart, Photon-Electric Pasteurization Corporation (US) ${ }^{*}$, N. G. Tolstun, NIIEFA Delta (RF)
}

\begin{abstract}
The economics of cold food pasteurization are governed by a number of factors, including: the type of ionizing radiation source (X-Ray, or Gamma), cost and power of the source, pasteurization dose, location of the pasteurization facility, facility capacity factor, and the annualized costs. Using a costing procedure developed by Morrison [1], calculations for typical sources, locations, etc., have been updated using facility cost estimates prepared by a major U.S. construction firm and scalings from the Morrison data.
\end{abstract}

The "owner's cost" per pound of product is a function of the facility scale, showing an asymptote at $\sim 100 \mathrm{kT}$ (220 million pounds) per year of product. Likewise, the owner's cost significantly depends on the annualization interest rate. A "stand-alone" location of the pasteurization facility has an effect on the cost of the process due to the need to transport product from the meat plant to the facility, the labor for unloading and loading the product at the facility, and the unshared G\&A costs at the facility. This increases processing costs and "borrows" into the shelf-life value of the product. An "integrated" location of the pasteurization facility (at the meat plant) minimizes processing cost (inclusive of special labeling) and best fits the operating characteristics of a typical meat plant (2 shift, 5 day week).

\section{INTRODUCTION}

Food irradiation has been thoroughly demonstrated to significantly reduce food contamination by pathological organisms by five orders of magnitude or more and extend shelf-life. Irradiation may be performed by: electronbeams, radioisotope gamma decay, and $\mathrm{X}$-rays. The first is the most efficient in terms of energetics but has serious limitations on product thickness, homogeneity (e.g., need for boneless product), and packaging. The second is the "standard" of the irradiation industry. The third has been made possible by recent advancements in electron-beam source power sizes, costs, and energies.

We analyze the radioisotope and $\mathrm{X}$-ray options as we conclude that only these meet the current and future requirements of the food manufacturing industry - penetrating, uniform, and cost-effective irradiation of food products in final shipping boxes. Electron-beams are limited to product thickness of $\sim 3$ inches in comparison with tens of inches for X-rays and Gamma rays.

\footnotetext{
* - elbogart@aol.com
}

X-ray machines come in "unit sizes" as they are designed for a certain maximum power. Radioisotope machine power is a function of the inventory of radioactive material (e.g., Co-60) which can be adjusted in facility design to meet the specific throughput requirements of a food manufacturing facility. Thus, to meet the needs of a specific facility, an X-ray machine may operate at less than its rated power output. This fact affects economic comparisons unless care is taken to fit the current accelerator technologies with the market needs.

Finally, irradiation plant scale and capacity factor affect food irradiation economics. Morrison showed that economies of scale essentially vanish after a plant processes on the order of 200 million pounds per year. We restrict our analysis to plants for which economies of scale should not be in effect. We capture plant capacity factor with two scenarios -3 and 2 shift per day operation. The former fully utilizes the capital equipment. The latter is better suited to most meat plants in the U.S.

\section{THE MODEL}

We use the costing formalism developed by Morrison in 1989 and updated in the recent "Proposed Rules" [2] published by the USDA for "Irradiation of Meat and Meat Products." For "sources," we use X-rays and Co-60 with cost estimates for the former from a survey in 1996 and for the latter, from Morrison. For the "balance of plant" (including shielding, machinery, related expenses, escalation, fees, etc.) we use a hybrid of costs - some scaled from Morrison and others from estimates of a US Engineering \& Construction firm. While the model is complex due to this "hybridization," care has been taken to properly allocate costs and escalation expenses.

The source characteristics are presented in Table 1. We treat three sources - a low-cost/high-power accelerator, a high-cost/low-power accelerator, and Cobalt-60. As a special case, we also assess the effect of the high-cost accelerator operating at $7.5 \mathrm{MeV}$ versus the current limit of 5.0 $\mathrm{MeV}$. For Cobalt-60 irradiators, we "scale" the facility with the Cobalt loading required to meet the throughput and assign a nominal price for the source material at $\$ 1.20 / \mathrm{Ci}$.

The case parameters presented in Table 2 correspond to the two highest through-put Morrison cases (208 and 416 million pounds per year for poultry). For an "integrated" plant (irradiation performed at the meat manufacturing facility), the lower of the two throughput cases (190 Tonne/shift) would meet the needs of $\sim 1 / 2$ of the ground meat production facilities in the U.S. For the higher 
throughput level (380 Tonne/shift), there is no known plant in the U.S. requiring this production level at this time. Thus, such an integrated facility would be expected to irradiate other beef products as well. For poultry, the low throughput rate for the integrated plant would meet the needs of virtually all of the current U.S. manufacturing facilities. The "stand-alone" plants have lower hourly throughput rates as they run three versus two shifts for the same annual production rates. On a shift basis, they are better sized for a large fraction of U.S. meat manufacturers.

Table 1 - Irradiation Source Parameters

\begin{tabular}{|l|c|c|c|}
\multicolumn{1}{|c|}{ Source Parameters } & Low-Cost Accelerator & High-Cost Accelerator & Radioisotope Co-60 \\
\hline Unit Power $(\mathrm{kW})$ & 500 & 200 & As Req. \\
\hline Unit Cost $(1000 \$$ or $\$ / \mathrm{Ci})$ & 2000 & 4000 & 1.2 \\
\hline Unit Cost $/ \mathrm{kW}$ of E-beam $(1000 \$ / \mathrm{kW})$ & 4 & 20 & NA \\
\hline Unit Cost $/ \mathrm{kW}$ of X-ray/Gamma-ray $(1000 \$ / \mathrm{kW})$ & 60 & 240 & 80 \\
\hline Net Utilization Efficiency & 0.4 & 0.4 & $0.25-0.4$ \\
\hline Unit Cost/kW of X-ray: $7.5 \mathrm{MeV}(1000 \$ / \mathrm{kW})$ & & 155 & \\
\hline
\end{tabular}

Table 2 - Case Parameters

\begin{tabular}{|c|c|c|c|}
\hline Sources & \multicolumn{2}{|c|}{ Balance of Plant } & Notes \\
\hline$\underline{\mathrm{X} \text {-Ray }}$ & \multicolumn{2}{|c|}{$\begin{array}{l}\text { Based on Current A\&E Costs } \\
\text { Based on Product Throughput }\end{array}$} & Based on Accelerator Unit Sizes \\
\hline Radioisotope (Gamma) & \multicolumn{2}{|c|}{$\begin{array}{l}\text { Scaled from } 1989 \text { Morrison } \\
\text { Based on Product Throughput }\end{array}$} & Based on Product Throughput \\
\hline \multicolumn{4}{|l|}{ Plant Type } \\
\hline $\begin{array}{l}\text { Stand Alone } \\
\text { (Three } 7 \text { Hour. Shifts) }\end{array}$ & $\frac{\text { Low Rate }}{\text { (Tonne/Shift) }}$ & $\begin{array}{l}\text { High Rate } \\
\text { (Tonne/Shift) }\end{array}$ & 225 to 450 Million Pounds per year \\
\hline Adders to Irradiation & 130 & 260 & 0.2 Cents each for transportation and labeling \\
\hline $\begin{array}{l}\text { Integrated } \\
\text { (Two } 8 \text { Hour Shifts) } \\
\text { Adders to Irradiation }\end{array}$ & 190 & 380 & $\begin{array}{l}215 \text { to } 430 \text { Million Pounds per year } \\
0.2 \text { Cents for labeling }\end{array}$ \\
\hline \multicolumn{4}{|l|}{ Major Cost Variables } \\
\hline $\begin{array}{l}\text { Annualization } \\
\text { Interest Rate }(\%)\end{array}$ & 5 to 15 & 5 to 15 & All Cases \\
\hline Dose $(\mathrm{kGy})$ & 2 to 3 & 2 to 3 & Range for Selected Cases - 2.5 Nominal \\
\hline Cost of Cobalt $(\$ / \mathrm{Ci})$ & 1.2 to 1.5 & 1.2 to 1.5 & Range for Selected Costs -1.2 Low \\
\hline
\end{tabular}

As noted in Table 2, the "source" scaling is based on integer accelerator sizes and continuous Cobalt-60 requirements. This means that, for Cobalt-60, the radiative power will exactly meet the selected processing rate requirements but, for the accelerators, the available radiative power will always exceed the required power for the selected processing rate - e.g., the capacity factor for the accelerator plant will be less than one for both integrated and stand-alone plants.

Costs for the X-ray plant "balance of plant" were developed from estimates prepared in 1998 by a U.S. architect $\&$ construction firm and are linearly scaled according to plant hourly throughput. For the Cobalt-60 plant, we used the 1988 Morrison estimates escalated to 1999 at 4 percent per year and, again, linearly scaled according to plant hourly throughput. For the plant processing rates analyzed, these linear scalings are justified as there were no economies of scale (capital cost) above Morrison's 208 million pound/year throughput.
Costs for transportation (stand-alone plant) and labeling (both plants) were taken from the USDA promulgation of the proposed meat irradiation rules $-\$ 0.002 / \mathrm{lb}$ each. We accept these estimates, but note that they will be product and process-specific. We also note that no costs were provided for the development and production of packaging materials that may be required for irradiation. We examine the parametric variation of unit costs $(\$ / \mathrm{lb})$ as a function of "interest rate" used to calculate the annualized costs. Morrison assumed 5\% which we felt was low in comparison with the food industries' required rate of return. An interest rate of $15 \%$, the upper bound, still may be too low. Finally, our model includes the capability to assess the effect of dose and Cobalt costs, etc., on overall costs. We do not parametrically assess these effects, but use them to examine special cases.

\section{RESULTS}

Table 3 presents the parametric results for both capital investment and unit costs. For the former, it is evident that 
the flat economies-of-scale prevail in the stand-alone plant and, to a lessor extent, in the integrated plant - the latter is due to a better fit of integer accelerators with plant requirements at higher throughput.

Table 3 - Parametric Analysis Results

\begin{tabular}{|c|c|c|c|c|c|c|}
\hline Plant Type $\rightarrow$ & \multicolumn{3}{|c|}{ Stand Alone Plant (3 shift/day) } & \multicolumn{3}{|c|}{ Integrated Plant (2 shift/day) } \\
\hline & $\begin{array}{l}\text { Low-cost } \\
\text { Accelerator }\end{array}$ & $\begin{array}{l}\text { High-cost } \\
\text { Accelerator }\end{array}$ & $\begin{array}{c}\text { Radioisotope } \\
\text { Cobalt-60 }\end{array}$ & $\begin{array}{l}\text { Low-cost } \\
\text { Accelerator }\end{array}$ & $\begin{array}{l}\text { High-cost } \\
\text { Accelerator }\end{array}$ & $\begin{array}{c}\text { Radioisotope } \\
\text { Cobalt-60 }\end{array}$ \\
\hline Costs $\downarrow$ & \multicolumn{3}{|c|}{130 T/Shift } & \multicolumn{3}{|c|}{190 T/Shift } \\
\hline Investment (Million \$) & 5.74 & 12.16 & 8.50 & 8.47 & 16.97 & 10.64 \\
\hline & \multicolumn{3}{|c|}{ Total Cost (Cents/lb) } & \multicolumn{3}{|c|}{ Total Cost (Cents/lb) } \\
\hline Annualization Rate $-5 \%$ & 1.13 & 1.59 & 1.41 & 0.96 & 1.56 & 1.33 \\
\hline Annualization Rate $-10 \%$ & 1.23 & 1.78 & 1.55 & 1.10 & 1.84 & 1.51 \\
\hline Annualization Rate $-15 \%$ & 1.33 & 2.00 & 1.71 & 1.25 & 2.15 & 1.71 \\
\hline & \multicolumn{3}{|c|}{260 T/Shift } & \multicolumn{3}{|c|}{380 T/Shift } \\
\hline Investment (Million \$) & 11.48 & 24.31 & 17.00 & 14.67 & 29.33 & 21.27 \\
\hline & \multicolumn{3}{|c|}{ Total Cost (Cents/lb) } & \multicolumn{3}{|c|}{ Total Cost (Cents/lb) } \\
\hline Annualization Rate $-5 \%$ & 1.03 & 1.48 & 1.30 & 0.81 & 1.33 & 1.26 \\
\hline Annualization Rate $-10 \%$ & 1.12 & 1.67 & 1.44 & 0.93 & 1.57 & 1.44 \\
\hline Annualization Rate $-15 \%$ & 1.22 & 1.89 & 1.60 & 106 & 184 & 1.64 \\
\hline
\end{tabular}

In contrast with intuition, the stand-alone plant has poorer performance than the integrated plant. This is due to the relatively low annualized irradiation costs in comparison with the transportation cost "adder" for the standalone plant versus the lower annual costs for the integrated plant from reduced manpower.

The interest rate for annualizing costs is seen to have a significant effect for the higher cost plants. However, the overall unit costs for all cases are quite small and the extrema differ by only $\sim 1.2$ cent over the parametric range. The low-cost, high-power accelerator offers the minimum cost, followed by Cobalt-60, with the high-cost/low-power accelerator being the highest.

A calculation was made for the high-cost/low-power accelerator at $7.5 \mathrm{MeV}$ for product throughputs that resulted in a nearly integer number of accelerators at an interest rate of $10 \%$ (midrange) to determine if this higher energy operation had a significant effect on unit costs. For the stand-alone plant, the unit costs were 1.54 and 1.41 cents/lb for processing rates of 104 and 208 Tonne/shift, respectively. For the integrated plant, the unit costs were $1.38,1.25$, and 1.19 cents/lb for processing rates of 119 , 238, and 476 Tonne/shift, respectively. This resulted in costs that were competitive to Cobalt-60 for the standalone plant and less expensive than Cobalt- 60 for the integrated plant (but still more costly than the low-cost/highpower accelerator).

A special case was run to assess the effect of a higher Net Utilization Efficiency (40\%) for Cobalt-60, based on reports that near $40 \%$ had been demonstrated in existing plants. At a $10 \%$ interest rate, this reduced the costs of Cobalt-60 irradiation to 1.32 and 1.21 cents/lb for the stand-alone plant and 1.17 and 1.10 cents/lb for the integrated plant. These are significant improvements.
Last, a case was run to assess the effect of higher dose (3.5 kGy) for an interest rate of $10 \%$. For the twelve cases at $10 \%$ in Table 3, the average increase in unit cost was less than $20 \%$ for the $40 \%$ increase in dose. This is due to the significance of the costs unrelated to the irradiation process - e.g., labeling and transportation.

\section{CONCLUSIONS}

Irradiation costs in general:

- Annualized irradiation unit costs are very low in comparison with product production costs. However, the cost differences between technologies can be $\$ 1-2$ million/year;

- Packaging and transportation costs significantly add to irradiation costs. Other costs, such as oxygen control, may increase unit costs;

- Capital cost differences may be the major selection discriminator because of low unit costs;

- Integrated irradiators have lower unit costs because of lower transportation and manpower costs.

Irradiation costs for specific technologies:

- The least-cost technology is the low-cost accelerator, followed by Cobalt- 60 then the high-cost accelerator;

- X-ray machine selection should be made to meet the processing requirements of meat production plants;

- Irradiation environment optimization should be performed for all irradiation technologies.

\section{REFERENCES}

[1] Morrison, R.M. "An Economic Analysis of Electron Accelerators and Cobalt-60 for Irradiating Food," USDA, TBN 1762, 1989.

[2] Proposed Rules, USDA, Food Safety and Inspection Service, RIN 0583-AC50, "Irradiation of Meat and Meat Products." 